\title{
Forming a Unitary Envelope Thermal Performance Index for Office Buildings in Taiwan
}

\author{
Ruey-Lung Hwang ${ }^{1}$, Ming-Chin $\mathrm{Ho}^{2}$, I-Ting Lai ${ }^{3}$, Kuo-Tsang Huang ${ }^{3}$ \\ ${ }^{1}$ Department of Industrial Technology Education, National Kaohsiung Normal University, \\ Kaohsiung, Taiwan \\ ${ }^{2}$ Department of Architecture, China University of Technology, Taipei, Taiwan \\ ${ }^{3}$ Department of Bioenvironmental Systems Engineering, National Taiwan University, Taipei, \\ Taiwan
}

\begin{abstract}
It is a crucial method to mitigate greenhouse gas emission and save building energy by complying the formulated regulations on buildings' envelope efficiency design. The existing Taiwanese building technical regulation provides three evaluation alternatives to comply with while developing a building envelope design scheme. Each evaluation alternative uses different index to direct a building's envelope energy efficiency design. However, it exhibits inconsistencies among these alternative methods including the use of different building design and climatic parameters, which would result in counterintuitive contradictions in some certain evaluation cases. To solve this phenomenon, this study attempts to integrate the three evaluation methods and propose a new index to regulate the building envelope's energy efficiency design.
\end{abstract}

\section{Introduction}

The Taiwanese government has released an annual energy consumption performance index to assess the thermal performance of building envelopes in 1995. The method has provided a maximum allowable annual sensible cooling load for the perimeter of a building. The sensible cooling load in the perimeter of a proposed building, over a whole year, must be lower than the benchmark value designated for the climates of different regions. This method allows for a trade-off between some design factors, such as window openings and external walls, to preserve some design flexibility. Taiwan's currently inforce building performance index is called ENVLOAD (Ministry of the Interior of Taiwan, 2011), which is calculated using Equations 1-5.

$$
\begin{gathered}
E N V L O A D=-20370+2.010 \cdot I G+0.033 L \cdot C D H \\
+1.079 \sum_{i} M_{i} \cdot S F_{i} \\
I G=13.5\left(a_{0}+a_{1} \cdot T_{u}+a_{2} \cdot T_{u}^{2}\right) \\
T_{u}=\frac{13.5}{L} \\
L=\frac{\sum_{i}\left(U_{w, i} A_{w, i}\right)+0.5 \sum_{i}\left(U_{w, i} A_{w, i}^{\prime}\right)}{A_{p}}+ \\
\frac{\sum_{i}\left(U_{f, i} A_{f, i}\right)+0.5 \sum_{i}\left(U_{f, i} A_{f, i}^{\prime}\right)}{A_{p}}+1.011
\end{gathered}
$$

$$
\begin{aligned}
& M=\frac{\sum_{i}\left(K_{i} \eta_{i} A_{f, i}\right)+0.5 \sum_{i}\left(K_{i} \eta_{i} A_{f, i}^{\prime}\right)}{A_{p}}+ \\
& \frac{0.035\left[\sum_{i}\left(U_{w, i} A_{w, i}\right)+0.5 \sum_{i}\left(U_{w, i} A_{w, i}^{\prime}\right)\right]}{A_{p}}
\end{aligned}
$$

where, $I G$ is the internal heat gain in $\mathrm{W} / \mathrm{m}^{2} \mathrm{~K} ; L$ is the heat loss factor of building envelope in $\mathrm{W} / \mathrm{m}^{2} \mathrm{~K} ; C D H$ is the annual total cooling degree-hours based on $23^{\circ} \mathrm{C} ; M_{i}$ is the solar heat gain corrected factor of $i$ orientation of the building envelope; $S F_{i}$ is the annual total solar insolation of $i$ orientation in $\mathrm{Wh} / \mathrm{m}^{2} ; T_{u}$ is the average room temperature increment in ${ }^{\circ} \mathrm{C} ; a_{0}$ to $a_{2}$ are regression coefficients; $U_{W}$ is the thermal transmittances of external walls in $\mathrm{W} / \mathrm{m}^{2} \mathrm{~K} ; U_{f}$ is the thermal transmittances of external windows in $\mathrm{W} / \mathrm{m}^{2} \mathrm{~K} ; K_{i}$ is the external sunshade shading coefficient of $i$ orientation; $A_{w}$ is the areas of the external walls for air-conditioned zones in $\mathrm{m}^{2} ; A_{w}^{\prime}$ is the areas of the external walls for non-air-conditioned zones in $\mathrm{m}^{2} ; A_{f}$ is the areas of fenestrations for air-conditioned zones in $\mathrm{m}^{2} ; A_{f}^{\prime}$ is the areas of fenestrations for non-airconditioned zones in $\mathrm{m}^{2} ; A_{p}$ is the total floor area of the air-conditioned perimeter zone in $\mathrm{m}^{2}$.

In Equation 1, the ENVLOAD equation was developed based on numerous building cooling load simulation cases and was established using multiple regression technique. It includes three terms, i.e. the $G, L \cdot C D H$, and $M i \cdot S F i$ terms, the first term denotes to the annul internal heat loads from the occupants, lighting, and equipment; the second term stands for the heat insulation capabilities of a given building; and the third term accounts for the building's solar shading capabilities.

In the 1990s, after Taiwan began using ENVLOAD as the thermal performance index of envelopes, other than the simplified correction proposed by Wang and Lin (2015) and the natural ventilation correction coefficient proposed by Lai (2008), it has not been further subjected to review or correction. Some studies have extended the applications of ENVLOAD. For example, Hwang and Hsu (2011) used a visitor center as an example to explore the influence of ENVLOAD on air conditioning energy consumption and indoor thermal comfort. Chen and Lin (2017) established a method to predict the maximum air conditioning load using the ENVLOAD indicator. Shih et al. (2018) combined building energy simulation techniques through an uncertainty analysis to prove that both ENVLOAD and the overall thermal transfer value 
(OTTV), both envelope thermal performance indices commonly used in Southeast Asian countries, can be converted into each other. Hwang et al. (2018) suggested that OTTV can be used to replace ENVLOAD; they analyzed a correction for the OTTV calculation formula and generated a benchmark value in response to future climate warming.

However, the evaluation equations of ENVLOAD are too numerous and there are too many variable combinations, leading to a complicated calculation and a cumbersome use of look-up tables. The equations are thus inconvenient to use in practice. Therefore, another aim of this study is to formulate and specify a new index equation for the thermal performance of a building envelope that can account for the accuracy of the prediction, while simultaneously being succinct and convenient to use.

\section{Methods}

\section{Definition of the performance metric}

In order to eliminate problems caused by the derivation of meteorological parameters $(C D H$ and $S F)$, one of the solutions is to change the current passing standard (the requirement that the annual sensible cooling load for the perimeter of a proposed building be lower than a certain benchmark value) to a new requirement (that the ratio of annual sensible cooling loads for perimeter zones between a proposed building and a specific baseline building, called the performance rating (PR), be lower than a certain value). In this paper, the performance rating is the main basis for developing the envelope performance index. The performance rating for each side of a proposed building's envelope is defined as:

$$
P R=100 \times\left(\frac{L_{p}}{L_{b}}-1\right)
$$

where, $L_{p}$ refers to the annual sensible cooling load per square meter of envelope area in the perimeter of a proposed building; and $L_{b}$ refers to the annual sensible cooling load per square meter of floor area in the perimeter of a baseline building.

The seasonal sensible cooling load per square meter of floor and envelope area in the perimeter is expressed in Equation 7. SC is the product of the glazing shading coefficient and the external sunshade shading coefficient, i.e., $\mathrm{SC}=0.87 \eta$. SF is the solar radiation incident on the south-facing external wall during the cooling season. $C F$ is the correction factor for the solar radiation azimuth, which is defined as the ratio of all-season solar radiation incident in any orientation to the solar radiation incident from the south. The $\mathrm{WWR}, \mathrm{U}_{\mathrm{W}}, \mathrm{U}_{\mathrm{f}}$, and $\eta$ are varied simultaneously to generate a sufficient number of proposed building cases; the $L_{p}$ of these cases is obtained by performing energy consumption simulations. The numerical values of $\sum\left(\mathrm{T}_{\mathrm{e}}-\mathrm{T}_{\mathrm{i}}\right), \sum\left(\mathrm{T}_{0}-\mathrm{T}_{\mathrm{i}}\right), \sum \mathrm{SF}_{\mathrm{o}}$, and $\sum \mathrm{IG}$ in Equation 7 can be obtained using regression analysis. In the above terms, the $T_{e}$ denotes equivalent temperature, $T_{i}$ is the indoor temperature, $T_{o}$ is the outdoor ambient temperature.
The sensible cooling load per square meter of external wall area in the perimeter of a baseline building is the numerical value of the sensible cooling load obtained by substituting $\mathrm{WWR}=0.31, \mathrm{U}_{\mathrm{W}}=0.857 \mathrm{~W} / \mathrm{m}^{2} \mathrm{~K}, \mathrm{U}_{\mathrm{f}}=3.24$ $\mathrm{W} / \mathrm{m}^{2} \mathrm{~K}, \mathrm{~K}=1, \eta=0.25$, as well as the average $C F$ corresponding to the proposed building's orientation at azimuths of $90^{\circ}, 180^{\circ}$, and $270^{\circ}$, into Equation 7.

$$
\begin{aligned}
& L_{p}=(1-W W R) U_{W} \sum\left(T_{e}-T_{i}\right) \\
& +W W R \cdot \mathrm{U}_{f} \sum\left(T_{o}-T_{i}\right)+S C \cdot C F \cdot W W R \sum S F_{o} \\
& +\sum I G
\end{aligned}
$$

In fact, the average value of the $4 \mathrm{CF}$ s obtained from the rotation $0^{\circ}, 90^{\circ}, 180^{\circ}$, and $270^{\circ}$ is almost equal to the average values at all orientations. As for the baseline buildings in any climate, since the WWR, $\mathrm{U}_{\mathrm{W}}, \mathrm{U}_{\mathrm{f}}, \mathrm{K}, \eta$, and $C F$ substituted into Equation 7 are constant, meaning that $L_{b}$ is also a constant value, only the constant $L_{b}$ value will differ with different climates. Therefore, the PR defined in Equation 6 can be expressed as:

$$
\begin{aligned}
& P R=\left[\frac{100 \sum\left(T_{e}-T_{i}\right)}{L_{b}}\right](1-W W R) \cdot U_{w}+ \\
& {\left[\frac{100 \sum\left(T_{o}-T_{i}\right)}{L_{b}}\right] \cdot W W R \cdot T D \cdot U_{f}+} \\
& \left(\frac{100 \sum S F}{L_{b}}\right) \cdot W W R \cdot S C \cdot C F+100\left(\frac{\sum I G}{L_{b}}-1\right)
\end{aligned}
$$

In the same way, the numerical values of $100 \sum\left(\mathrm{T}_{\mathrm{e}}-\mathrm{T}_{\mathrm{i}}\right) / L_{b}$, $\left.100 \sum\left(\mathrm{T}_{\mathrm{o}}-\mathrm{T}_{\mathrm{i}}\right) / L_{b}, \quad 100 \sum \mathrm{SF}\right) / L_{b}$, and $100\left(\sum \mathrm{IG} / L_{b}-1\right)$ in Equation 8 can be obtained by regression analysis as long as there are sufficient PRs in the proposed buildings.

\section{Building model}

The required performance index equation is obtained in this paper by using EnergyPlus to conduct simulations on the energy consumption of an office building model. The typical office building model shown in Figure 1 is used. The typical building plan is divided into 4 air-conditioned perimeter zones, as well as other zones with innerperimeter air-conditioned spaces and non-air-conditioned spaces, such as stairs, elevators, or restrooms. Perimeter zones refer to indoor spaces within a distance of $5 \mathrm{~m}$ from external walls, which are susceptible to the heat flow entering from the envelope. The 4 air-conditioned perimeter zones are spaces of interest and are analyzed in this paper. The other zones are not considered and outside the scope of the energy consumption simulations. The local meteorological data of a typical meteorological year (TMY3) has been used, assuming that the building is located in three climate regions in Taiwan represented by three cities: Taipei, Taichung, and Kaohsiung. The climatic and geographical properties are briefly summarized in Table 1.

As the focus of this study is to formulate and specify a new index equation for the thermal performance of a building envelope, the methodology is based on energy simulations conducted for a large number of different office building models, as well as multiple regression 
analyses. Therefore, the parameters involved are the ambient temperature of the building's location, the intensity of the solar radiation, the orientation of envelope, the window to wall ratio (WWR), the wall's U-value ( $\left.U_{W}\right)$, the glazing's U-value $\left(\mathrm{U}_{\mathrm{f}}\right)$, the glazing's SHGC, and the external sunshade depth ratio. These 6 parameters are also the architectural design parameters used in the calculation of the ENVLOAD index.

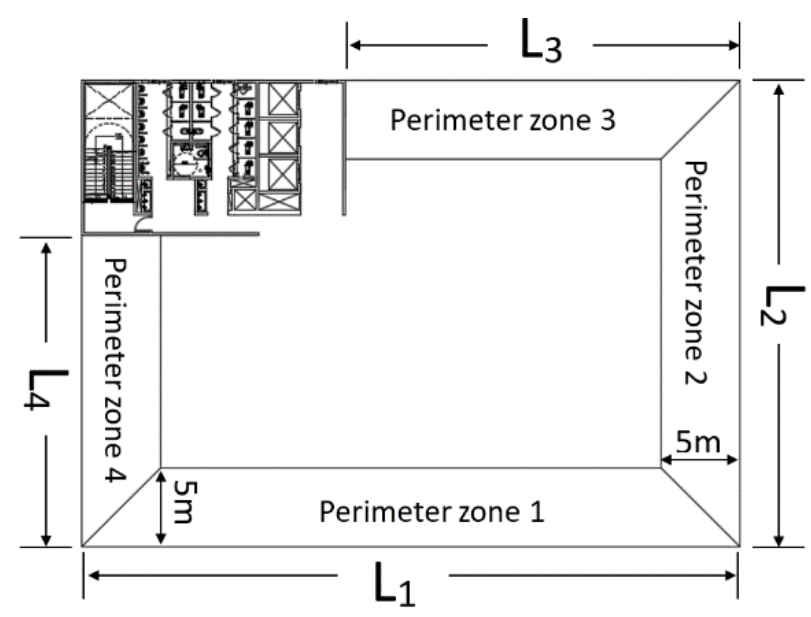

Figure 1: Floor plan of the typical office building.

Table 1: Summary of the geographical data and the climate of the studied cities.

\begin{tabular}{|c|c|c|c|c|}
\hline Locations & Coordinates & $\begin{array}{c}\text { Annul } \\
\text { HDD }_{18} \\
\text { (K.hrs) }\end{array}$ & $\begin{array}{c}\text { Annual } \\
\text { CDD } 18 \\
\text { (K.hrs) } \\
\text { global } \\
\text { horizontal } \\
\text { solar } \\
\text { radiation } \\
\text { (kW/m } \mathbf{2}\end{array}$ \\
\hline Taipei & $\begin{array}{l}\text { N25.0, } \\
\text { E121.5 }\end{array}$ & 194 & 2139 & 6641.9 \\
\hline Taichung & $\begin{array}{l}\text { N24.1, } \\
\text { E120.7 }\end{array}$ & 134 & 2344 & 8572.9 \\
\hline Kaohsiung & $\begin{array}{l}\text { N22.6, } \\
\text { E120.3 }\end{array}$ & 25 & 2768 & 7914.5 \\
\hline
\end{tabular}

In order to obtain a sufficient number of building models, this paper uses Latin hypercube sampling from a uniform distribution to generate 1,000 simulated samples with different combinations of envelope thermal performances. Table 2 shows the range of variation for these input variables. Other variables, such as the internal load and the air conditioning operative controls, are not included in the modelling process to facilitate observations of the unique effects of the passive thermal performance design on the annual sensible cooling load. The air-conditioning system was set to only operate on working days from May $1^{\text {st }}$ to September $30^{\text {th }}$ during the main cooling season; the operation time period is 07:00-19:00. Referring to the ASHRAE 62.1 Standard (2004), the fresh air exchange rate is provisioned to be $8.5 \mathrm{~L} / \mathrm{s}$ per person. The density of occupants is 0.15 person $/ \mathrm{m}^{2}$, the lighting density is 11.8 $\mathrm{W} / \mathrm{m}^{2}$, and the density of the office equipment heat generation is $12.5 \mathrm{~W} / \mathrm{m}^{2}$. The occupant, lighting, and equipment usage schedule are ascertained according to ASHRAE 90.1 Standard (2013). Since there are no provisions for the performance of a baseline building envelope in Taiwan, this paper directly adopts the relevant provisions of a baseline building envelope performance from ASHRAE Standard 90.1 appendix G; these provisions are listed in Table 2. The indoor thermostat control is a dry-bulb temperature control and is set at $24^{\circ} \mathrm{C}$ constant during the hot season.

\section{Results and Discussions}

\section{Simulation results}

In order to illustrate the uncertainty triggered by the architectural design parameters, variations in the seasonal sensible cooling loads per square meter of perimeter zone of all proposed building cases obtained from the EnergyPlus simulation, for all the three cities, are presented using histograms and statistical values. Figure 2 has shown the range of possible seasonal sensible cooling loads and the probability of each interval in the three cities. For the seasonal sensible cooling loads, the Taipei range is between $86 \mathrm{kWh} / \mathrm{m}^{2}$ and $182 \mathrm{kWh} / \mathrm{m}^{2}$, the Taichung range is between $87 \mathrm{kWh} / \mathrm{m}^{2}$ and $200 \mathrm{kWh} / \mathrm{m}^{2}$, and the Kaohsiung range is from $91 \mathrm{kWh} / \mathrm{m}^{2}$ to 189 $\mathrm{kWh} / \mathrm{m}^{2}$. Obviously, Taipei has the lowest seasonal sensible cooling loads and the largest loads occurred in Taichung. The mean seasonal sensible cooling loads for Taipei, Taichung, and Kaohsiung are $112 \mathrm{kWh} / \mathrm{m}^{2}, 118$ $\mathrm{kWh} / \mathrm{m}^{2}$, and $122 \mathrm{kWh} / \mathrm{m}^{2}$, respectively.

Table 2: The input variables, variation ranges, and the baseline values of the building model.

\begin{tabular}{|l|c|c|}
\hline \multicolumn{1}{|c|}{$\begin{array}{c}\text { Input } \\
\text { variables }\end{array}$} & Ranges & \multicolumn{1}{c|}{ Baseline values } \\
\hline $\begin{array}{l}\text { Orientation } \\
\text { (degree) }\end{array}$ & $\begin{array}{c}0^{\circ}, 45^{\circ}, \\
90^{\circ}, 135^{\circ}, \\
180^{\circ}, 225^{\circ}, \\
270^{\circ}, 315^{\circ}\end{array}$ & $\begin{array}{l}\text { The baseline building } \\
\text { performance shall be } \\
\text { generated by simulating the } \\
\text { building with its actual } \\
\text { orientation and again after } \\
\text { rotating the entire building } \\
90,180, \text { and } 270 \text { degrees, } \\
\text { then averaging the results. }\end{array}$ \\
\hline $\begin{array}{l}\text { Width of the } \\
\text { perimeter } \\
\text { zones }\end{array}$ & $\begin{array}{c}10-50 \\
(\mathrm{~m})\end{array}$ & $\begin{array}{c}\text { Same as the proposed } \\
\text { building design. }\end{array}$ \\
\hline $\begin{array}{l}\text { Window-to- } \\
\text { wall ratio }\end{array}$ & $0.1-0.9$ & 0.310 \\
\hline $\begin{array}{l}\text { U-value of the } \\
\text { exterior wall }\end{array}$ & $\begin{array}{c}0.5-5.0 \\
\left(\mathrm{~W} / \mathrm{m}^{2} \mathrm{~K}\right)\end{array}$ & $0.857\left(\mathrm{~W} / \mathrm{m}^{2} \mathrm{~K}\right)$ \\
\hline $\begin{array}{l}\text { U-value of the } \\
\text { fenestration }\end{array}$ & $\begin{array}{c}1.0-5.5 \\
\left(\mathrm{~W} / \mathrm{m}^{2} \cdot \mathrm{K}\right)\end{array}$ & $3.240\left(\mathrm{~W} / \mathrm{m}^{2} \mathrm{~K}\right)$ \\
\hline $\begin{array}{l}\text { SHGC of the } \\
\text { fenestration }\end{array}$ & $0.1-0.85$ & 0.25 \\
\hline $\begin{array}{l}\text { Depth ratio of } \\
\text { the exterior } \\
\text { shading }\end{array}$ & $0.0-2.0$ & no shading projections \\
\hline
\end{tabular}

The most commonly-seen seasonal sensible cooling load interval in Taipei, Taichung, and Kaohsiung are 110 $\mathrm{kWh} / \mathrm{m}^{2}, 110 \mathrm{kWh} / \mathrm{m}^{2}$, and $115 \mathrm{kWh} / \mathrm{m}^{2}$, respectively. Moreover, the difference between the minimum and maximum seasonal sensible cooling loads is also different among the three cities; they are $96 \mathrm{kWh} / \mathrm{m}^{2}, 113 \mathrm{kWh} / \mathrm{m}^{2}$, and $98 \mathrm{kWh} / \mathrm{m}^{2}$ for Taipei, Taichung, and Kaohsiung, 
respectively. The ratio of uncertainty can be defined by observing the standard deviations, which are $13 \mathrm{kWh} / \mathrm{m}^{2}$, $17 \mathrm{kWh} / \mathrm{m}^{2}$, and $16 \mathrm{kWh} / \mathrm{m}^{2}$, respectively.

The results presented in Figure 2 mean that the design parameters have a considerable influence on the variation of the seasonal sensible heat-cooling load. Therefore, the architect should confirm at the early design stage that the proposed building can provide a sufficient seasonal sensible heat-cooling load. By accounting for the local mandatory energy indices, architects can understand the possible range of seasonal sensible heat-cooling loads, because many of the energy indices have linear relationships with the seasonal sensible cooling load. Figure 3 is a scatter plot of the simulated annual sensible cooling load against ENVLOAD for the 3 cities, as obtained from the simulations on all the proposed building cases at $24{ }^{\circ} \mathrm{C}$. In the plot, the linear regressions of $L_{p}$ and ENVLOAD are also shown.

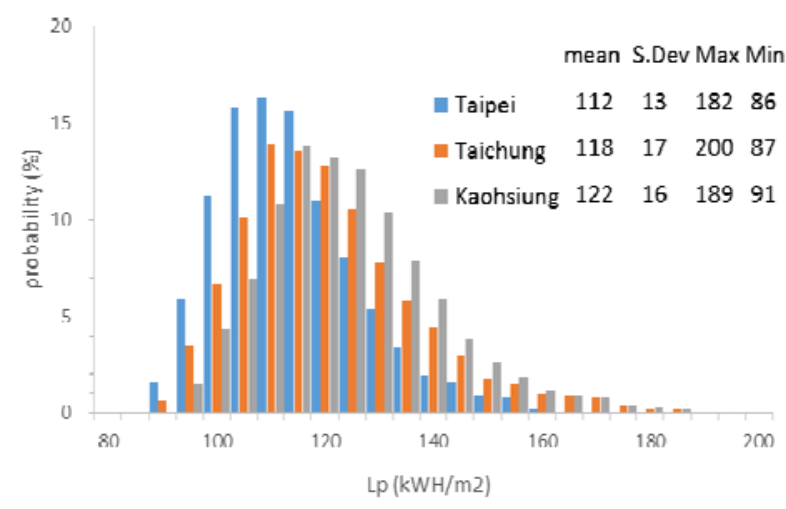

Figure 2: Variation of $L_{p}$ for all cases in the three cities.

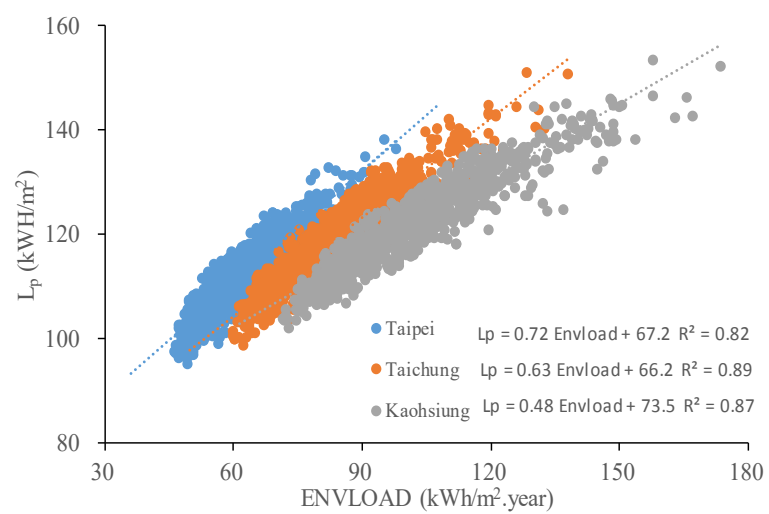

Figure 3: Scatter plots of $L_{p}$ against ENVLOADs in the three cities.

Using the results of these simulations, the $L_{p}$ equations for the three cities can respectively be obtained through regression analysis as:

Taipei:

$$
\begin{aligned}
& L p=6.3(1-W W R) U_{w}+2.7 W W R \cdot U_{f}+ \\
& 75.7 W W R \cdot S C \cdot C F+84.5 \quad \mathrm{R}^{2}=0.946
\end{aligned}
$$

Taichung:

$$
\begin{aligned}
& L p=7.5(1-W W R) U_{w}+2.1 W W R \cdot U_{f}+ \\
& 102.9 W W R \cdot S C \cdot C F+85.0 \quad \mathrm{R}^{2}=0.975
\end{aligned}
$$

Kaohsiung:

$$
\begin{gathered}
L p=7.8(1-W W R) U_{w}+3.7 W W R \cdot U_{f}+ \\
91.3 W W R \cdot S C \cdot C F+88.2 \quad \mathrm{R}^{2}=0.956
\end{gathered}
$$

\section{Establishing of a unitary envelope thermal} performance index

From the EnergyPlus simulation results of various proposed buildings corresponding to a baseline building, we discovered that the seasonal sensible cooling load per square meter for baseline buildings, $L_{b}$, is almost identical to the numerical values obtained by substituting the provisioned WWR, $\mathrm{U}_{\mathrm{W}}, \mathrm{U}_{\mathrm{f}}, \mathrm{K}, \eta$, and $\mathrm{CF}$ into Equations 9-11, where $L_{b}$ is $98.3 \mathrm{kWH} / \mathrm{m}^{2}$ in Taipei, $101.8 \mathrm{kWH} / \mathrm{m}^{2}$ in Taichung, and $105.6 \mathrm{kWH} / \mathrm{m}^{2}$ in Kaohsiung. By observing Figure 4, there are consistent PR probability distribution curves in the 3 investigated climate regions. Once again, the regression analysis is applied to the PRs of all proposed building cases, and the resulting regression formula is shown in Equation 12.

$$
\begin{gathered}
P R=7.1(1-W W R) U_{w}+2.8 W W R \cdot U_{f}+ \\
88.2 W W R \cdot S C \cdot C F-15.7 \quad \mathrm{R}^{2}=0.956
\end{gathered}
$$

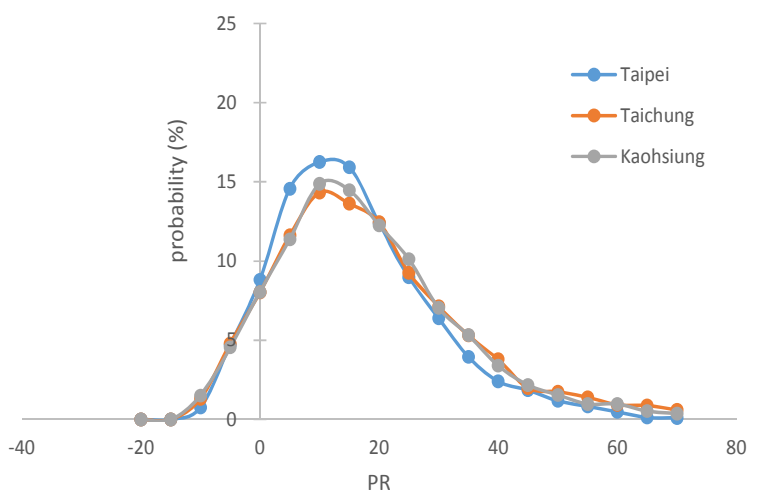

Figure 4: The probability distributions of PR of all the proposed cases in the three cities.

\section{Sensitivity analysis}

A sensitivity analysis is executed to ascertain the contribution of each input variable to the variation of the designated output of a building model. In this paper, the sensitivity index used is a standardized regression coefficient (SRC). A standardized regression coefficient is used to measure the linear influences of each input variable $\left(x_{j}\right)$ on the output variable $(y)$, and is calculated by Equation 13, where $\bar{x}_{j}$ and $\bar{y}$ are the averages of the input and output, respectively.

$$
S R C_{j}=\frac{\beta_{j} \sqrt{\sum_{i=1}^{N} \frac{\left(x_{i, j}-\overline{x_{j}}\right)^{2}}{N-1}}}{\sqrt{\sum_{i=1}^{N} \frac{\left(y_{i}-\bar{y}\right)^{2}}{N-1}}}
$$

While complying with local mandatory regulations, conducting sensitivity analyses on design parameters can assist an architect to examine the sensitive design parameters, so as to achieve a building possessing higher energy performance. During the building process, design requirements for the minimum cooling load can be 
obtained by selecting the upper limit of the design parameters with negative SRC and by selecting the lower limit of the design parameters with positive SRC. Moreover, the magnitude of the SRC absolute value represents the importance of the design parameter. Based on the simulation results, the results of the SRC are summarized in Table 3.

Table 3: SRC comparison between the dry-bulb based and the operative temperature based control method.

\begin{tabular}{|c|c|c|c|c|c|c|}
\hline Variables & $\mathrm{CF}$ & $\mathrm{WWR}$ & $\mathrm{U}_{\mathrm{W}}$ & $\mathrm{U}_{\mathrm{f}}$ & $\eta$ & $\mathrm{K}$ \\
\hline SRC & 0.23 & 0.49 & 0.24 & 0.11 & 0.52 & 0.37 \\
\hline
\end{tabular}

The glazing shading coefficient $(\eta)$ has the largest SRC value (0.52). This indicates that the glazing shading coefficient has the most influence on PR. The second and the third most influential are the window to wall ratio (WWR) and the external sunshade shading coefficient (K), followed by the external wall $\mathrm{U}_{\mathrm{W}}$ value, the window to wall ratio (WWR) and the fenestration $U_{\mathrm{f}}$ value. Though the value of the SRC for $U_{\mathrm{f}}$ is lower, its influence still needs to be considered.

\section{Conversion of the baseline values}

As a result of climate regions having different $C D H$ and $S F$, climate zoning requires different formulas and benchmark values, shown in Equations 9-11. Through the standardization of Equation 8, this paper has found a single formula that is applicable for the envelope performance index of all cities in Taiwan, i.e., Equation 12 can be used as the single envelope performance index in Taiwan. The logic that converts the benchmark ENVLOAD to the benchmark PR is explained below. Taking Taipei City as an example, the benchmark ENVLOAD is $90 \mathrm{kWh} / \mathrm{m}^{2}$ year. Based on the linear regressions of $L_{p}$ and ENVLOAD in Figure 3, the corresponding $L_{p}=124.8 \mathrm{kWh} / \mathrm{m}^{2}$ year can be obtained. For the baseline buildings in Taipei, $L_{b}=98.3 \mathrm{kWh} / \mathrm{m}^{2}$ and PR $=100 *(124.8 / 98.12-1)=27.0$. This numerical value is the PR benchmark value corresponding to the currently inforce ENVLOAD benchmark value for the Taipei region. Benchmark values for PR in Taichung and Kaohsiung are 16.8 and 21.9 , respectively.

Equation 12 is used as a formula because it can eliminate problems caused by a one-calculation-formula for oneclimate-zone for different climates. Furthermore, the relative standards used in $\mathrm{PR}$ are unlike the absolute standards used in ENVLOAD; its benefits can help Government construction management units to understand the stringent standards required for benchmark values in different climates. For example, if the standard values of ENVLOAD in the three regions are 80,90 , and $115 \mathrm{kWh} / \mathrm{m}^{2}$ year, it is easy to misinterpret that there are stricter standards in Taipei, and that Kaohsiung has a more lenient standard. However, PR tells us that, actually, the currently in-force Taiwan standard is the most lenient for Taipei, because it has the highest value calculated using the same index formula. This indicates that, in a given proposed building, for Taichung or Kaohsiung climates, there must be more stringent requirements for external wall $U_{W}$ as well as window $U_{f}$ and $\mathrm{SC}$ in order to pass the mandatory regulations. If the construction management unit wants to have consistent requirements throughout Taiwan, this can be achieved with a single PR throughout the whole country; however, this cannot be achieved by using a consistent ENVLOAD because its calculation directly involves the local climatic conditions. Another benefit of the PR is that it directly indicates the percentage of sensible cooling load allowed in the proposed building compared to the baseline building. According to current standards, Taipei allows a proposed building to be at more than $27.0 \%$, whereas Taichung and Kaohsiung only allow $16.8 \%$ and $21.9 \%$, respectively.

\section{Conclusion}

This study has expounded the problematic points of the currently in-force building envelope energy consumption index in Taiwan (ENVLOAD), including the cumbersomeness of the practical evaluation process and the presence of unequal benchmark values for each climate region. Therefore, this study proposed the development of a thermal performance evaluation index for new building envelopes based on the performance rating. The advantage in the proposed method relies on removing the meteorological parameters from the original ENVLOAD, while preserving the main envelope design factors that influence the thermal performance of a building. Simultaneously, it is simplified to a single formula for all of Taiwan, which can greatly reduce the complexity of the assessment. The newly proposed index includes all the six building and two meteorological parameters that are currently used in the three existing indices, including building orientation, window-to-wall ratio (WWR), U-value of the exterior walls, U-value of the window glazing, solar heat gain coefficient (SHGC) of the glazing, the exterior shading of the window, cooling degree hours, and annual solar insolation. At the same time, the existing ENVLOAD benchmark is converted and applied to the new index. This study has reached the following important conclusions:

1. This study develops a new building envelope thermal performance evaluation index through a performance-based rating system compared with a baseline building.

2. The study has shown that the stringency level of currently in-force ENVLOAD benchmarks is not uniform, being the most lenient for Taipei and the most stringent for Taichung among the examined cities. However, if PR is used as an evaluation index, the unfairness due to the non-uniform level of stringency for building envelope energy management, which is generated by climate induced variations in benchmarks, can be eliminated.

3. Through the sensitivity analysis in this study, the importance of various building envelopes designs to the cooling load is in the following order: $\eta$, WWR, external sunshade $\mathrm{K}$, and external wall $\mathrm{U}_{\mathrm{W}}$.

\section{References}

American Soceity of Heating, Refrigerating and AirConditioning Engineers (2004). Ventilation for 
Acceptable Indoor Air Quality (ASHRAE Standard 62.1-2004).

American Soceity of Heating, Refrigerating and AirConditioning Engineers (2013). Energy Standard for Buildings Except Low-Rise Residential Buildings (ASHRAE Standard 90.1-2013).

Chen Y.-R. and Lin H.-T. (2017). Forecasting the Maximum Heat Load of Air Conditioners Using the ENVLOAD: Case Studies of Department Stores and Office Buildings (in Chinese). Journal of Architecture 99, 21-35.

Hwang R.-L. and Shu S.-Y. (2011). Building envelope regulations on thermal comfort in glass facade buildings and energy-saving potential for PMV-based comfort control. Building and Environment 46, 824834.

Hwang R.-L., Shih W.-M., Lin T.-P., and Huang K.-T. (2018). Simplification and adjustment of the energy consumption indices of office building envelopes in response to climate change. Applied Energy 230, 460470.

Lai P.-H. (2008). Assessment on Ventilation Performance for Envload in Office Buildings (in Chinese). National Cheng Kung University, Tainan (Taiwan).

Ministry of the Interior of Taiwan (2011). Technical regulations on the design of the office building energy conservation (in Chinese).

Shih W.-M., Hwang R.-L., and Lin T.-P. (2018). Using Uncertainty Analysis to Discuss the Feasibility of Integration of Envelope Conservation Index between Taiwan and ASEAN (in Chinese). Journal of Architecture 103, 35-49.

Wang J.-C. and Lin H.-T. (2005). Research on the Simplification of ENVLOAD Estimation for Office Buildings (in Chinese). Journal of Architecture 53, 141-154. 